\title{
Población desplazada por la violencia: derecho a la tierra, vivienda digna y economía sostenible en el municipio de Saravena, Arauca, (Colombia)
}

\author{
Jairo Ardila González \\ Abogado, Especialista en Derecho Administrativo por la Universidad Santo Tomás Seccional Bucaramanga; \\ Especialización en Derechos Humanos (en curso), Universidad Santo Tomás Bogotá, en convenio con la Defensoría \\ del Pueblo - USAID - Unión Europea - Naciones Unidas - Ministerio del Interior y de Justicia. Defensor público \\ en el Programa de Representación Judicial a Victimas Menores de Edad y Violencia de Género - Regional Arauca, \\ Colombia.Correo electrónico: jairoardilagonzalez@hotmail.com
}

\begin{abstract}
Resumen
El reconocimiento de derechos a favor de la población en situación de desplazamiento se ha logrado, en su mayor parte, a través de los pronunciamientos de la Corte Constitucional; el presente artículo identifica esas garantías, en forma concreta las que surgieron con ocasión de la declaratoria del estado de cosas inconstitucional en la Sentencia T-025/2004. A su vez, en este escrito se exponen las condiciones o esquemas diseñadas por la Corporación Judicial en mención para el cumplimiento de las obligaciones que surgen a cargo de la Nación y las entidades territoriales, y que se dirigen a la satisfacción de los derechos de esa población y a la superación del estado de cosas. Finalmente, se realiza un estudio de caso en el cual se examina de qué manera el municipio de Saravena, Arauca ha dado cumplimiento a las necesidades de la población en situación de desplazamiento.

Palabras clave: Estado de cosas inconstitucional, caracterización, desplazamiento forzado y derecho a tierras.
\end{abstract}

\section{Summary}

The recognition of rights in favor of the displaced population has been achieved largely through the rulings of the Constitutional Court; This article identifies those guarantees, specifically those that emerged during the declaration of a state of unconstitutionality in Judgment T-025/2004. In turn, in this paper the conditions or schemes designed by the Judicial Corporation in question for the fulfillment of obligations arising by the Nation and territorial entities are exposed, and are directed to the satisfaction of the rights of that population and overcoming the status quo. Fnally a case study which examines how the municipality of Saravena (Arauca) has met the needs of the displaced population is made.

Keywords: Unconstitutional state of affairs, characterization, forced displacement and land rights.

\section{Résumé}

La reconnaissance des droits en faveur de la population déplacée a été réalisé en grande partie par les décisions de la Cour constitutionnelle; Cet article identifie ces garanties, en particulier celles qui ont émergé au cours de la déclaration de l'état d'inconstitutionnalité dans le jugement T-025/2004. À son tour, dans ce document, les conditions ou les systèmes conçus par la Société judiciaire en question pour le respect des obligations découlant de la Nation et des entités territoriales sont exposés, et sont dirigés vers la satisfaction des droits de cette population et de surmonter le statu quo. Enfn une étude de cas qui examine comment la municipalité de Saravena (Arauca) a répondu aux besoins de la population déplacée est faite.

Mots-clés: situation inconstitutionnelle, la caractérisation, les déplacements forcés et les droits fonciers. 



\section{Población desplazada por la violencia: derecho a la tierra, vivienda digna y economía sostenible en el municipio de Saravena, Arauca, (Colombia)*}

Jairo Ardila González

\section{INTRODUCCIÓN}

En Colombia, el conflicto interno armado que sostiene el Estado contra las fuerzas de izquierda y de derecha, ha generado diferentes fenómenos sociales, entre ellos el desplazamiento forzado por la violencia, hecho que afecta gravemente un número importante de familias dentro del territorio nacional; estas familias se han visto obligadas a abandonar sus domicilios, viéndose vulnerados en sus derechos fundamentales a tener dominio de tierras, vivienda digna y economías sostenibles, entre otros; esta condición de desplazados los ha colocado en una situación de precariedad social y moral, llevándolos inclusive a disolución de sus núcleos familiares, lesionando en especial los derechos de los menores de edad y población de avanzada edad, al igual que obligándolos a abandonar sus culturas indígenas o afrodescendientes.

Debido al incremento del fenómeno del desplazamiento forzado por la violencia, el Estado colombiano creó las leyes 387 y 418 de 1987, en las que reglamentó entre otras materias, la condición del desplazamiento forzado, la creación de un registro de víctimas y la entrega de ayudas humanitarias a las familias afectadas.

No obstante, las previsiones legales, las instituciones oficiales encargadas de atender a la población registrada como desplazados por la violencia, no cumplieron eficazmente el mandato ordenado por el legislador, razón por la cual, a partir del año 2000, un número superior a mil familias desplazadas por la violencia y residenciadas

El presente artículo de reflexión es producto de la investigación: Situación actual de la población desplazada por la violencia y residenciada en el municipio de Saravena (Arauca), con relación a los derechos a la tierra, vivienda digna y economía sostenible, realizada en la asignatura de Metodología de la Investigación, Especialización en Derecho Administrativo, Universidad Santo Tomás Seccional Bucaramanga, bajo la tutoría del docente Jaime Enrique Rodríguez Navas. 
en diferentes municipios del territorio nacional, se vieron obligadas a solicitar la tutela de sus derechos fundamentales, entre ellos, el derecho a tierras, vivienda digna y economía sostenible.

El curso de dichas acciones avocó a la Honorable Corte Constitucional revisar de manera especial el fenómeno, de tal modo, que mediante Sentencia T-025 de 2004 declaró que en Colombia existía un estado de cosas inconstitucional que afectaba gravemente a la población desplazada por la violencia y con motivo del conflicto interno armado. El problema social del desplazamiento forzado por la violencia se sintió con más fuerza en algunos departamentos como Arauca, y esto debido a la lucha armada entre el Estado y las guerrillas, el conflicto entre guerrillas, Fuerzas Armadas Revolucionarias de Colombia-FARC-y el Ejército de Liberación Nacional -ELN-, y el accionar paramilitar; de manera que municipios de dicha jurisdicción, como Saravena, se convirtieron en territorios expulsores, pero en adversa situación, debió ser receptor de un número significativo de familias que provenían de otros municipios, los cuales se vieron obligados a abandonar sus arraigos sociales y familiares para salvar sus vidas amenazadas por los diferentes actores del conflicto armado.

Teniendo en cuenta el gran número de familias desplazadas por la violencia, que hoy se encuentran residenciadas en el municipio de Saravena, Arauca, y que desde el año 2004 con fundamento en la Sentencia T-025 existen órdenes perentorias emanadas de la Honorable Corte Constitucional, las cuales debe hacer efectivas el Gobierno nacional, departamental y municipal. Se hace importante conocer cuál es el estado actual, que en materia del derecho a vivienda digna, derecho a tierras y derecho a economía sostenible, soporta la población desplazada por la violencia y residenciada en dicho municipio, al igual que conocer cuál ha sido la gestión administrativa del Gobierno nacional, departamental y municipal al respecto.

El presente artículo de investigación tiene cuatro propósitos: el primero, distinguir cuáles son los derechos que como consecuencia de la declaratoria del estado de cosas inconstitucional, son reconocidos por el Tribunal Constitucional colombiano a favor de las personas en situación de desplazamiento; el segundo, identificar las obligaciones que se generan a cargo de la Nación, los departamentos y municipios; el tercero, conocer las condiciones o esquemas diseñadas por la Corporación Judicial para que se puedan satisfacer los derechos de esa población y se supere el estado de cosa inconstitucional, y finalmente, realizar un estudio de caso en el cual se examine de qué manera el municipio de Saravena ha dado cumplimiento a las necesidades de la población en situación de desplazamiento.

En este sentido, el presente texto se estructura en dos capítulos: en el primero, se abordará lo correspondiente al estado de cosas inconstitucional; en el segundo, se estudiará lo concerniente a la situación de desplazamiento en el municipio de Saravena y la gestión administrativa de esa entidad territorial frente a los derechos de la población que se encuentra en esa condición. 
En este escrito se defiende la postura según la cual en el municipio, en forma específica, las autoridades que tienen a su cargo la administración de ese ente, pese a los mandatos de la Corte Constitucional y a pesar de contar con recursos económicos suficientes, no han dado cumplimiento al esquema diseñado en la Sentencia T-025/04 y en los autos de seguimiento, a fin de garantizar los derechos a la tierra, vivienda digna y economía sostenible de la población en situación de desplazamiento, y con ello aporta su cuota para contribuir a superar el estado de cosas inconstitucional.

La grave situación frente a la lesión de los derechos humanos a la población en situación de desplazamiento en nuestro país, la naturaleza de dichos derechos, el conflicto armado que aún persiste, dan cuenta de la importancia que reviste la realización de esta investigación.

\section{ESTADO DE COSAS INCONSTITUCIONALES - SENTENCIA T - 025 DE 2004}

En el año 2004, debido al gran número de acciones de tutelas promovidas por familias desplazadas por la violencia, quienes a lo largo y ancho del país reclamaban, entre otros, los derechos a vivienda digna, economía sostenible y dominio de tierras, derecho prescrito legalmente y que el Estado no les proveía oportunamente, obligó a la Corte Constitucional a revisar la situación de estos colombianos, y encontró que se estaba frente a un estado de cosas inconstitucionales; hecho que fue declarado mediante Sentencia T-025. La alta corporación impartió órdenes perentorias a los Gobiernos nacional, departamentales y municipales en materia de prevención y atención a la población afectada por dicho fenómeno; de la misma manera, se consolidó el seguimiento y vigilancia para el cumplimiento de las órdenes judiciales impartidas y, por ello, dentro del expediente señalado, se han proferido, entre otras, las siguientes providencias judiciales: 1) Auto 314 de 2009; 2) Auto 0383 de 2010, en los que concretó órdenes específicas en materia de tierras, vivienda, y economía sostenible, las cuales debían acatar las administraciones públicas del orden nacional y local.

La referida sentencia, de manera concreta rotuló cuáles eran los factores o elementos constitutivos del estado de cosas inconstitucionales, señalando:

Dentro de los factores valorados por la Corte para definir si existe un Estado de cosas inconstitucional, cabe destacar los siguientes: (i) la vulneración masiva y generalizada de varios derechos constitucionales que afecta a un número significativo de personas; (ii) la prolongada omisión de las autoridades en el cumplimiento de sus obligaciones para garantizar los derechos; (ii) la adopción de prácticas inconstitucionales, como la incorporación de la acción de tutela como parte del procedimiento para garantizar el derecho conculcado; (iii) la no expedición de medidas legislativas, administrativas o presupuestales necesarias para evitar la vulneración de los derechos; (iv) la existencia de un problema social cuya solución compromete la intervención de varias entidades, requiere 
la adopción de un conjunto complejo y coordinado de acciones y exige un nivel de recursos que demanda un esfuerzo presupuestal adicional importante; (v) si todas las personas afectadas por el mismo problema acudieran a la acción de tutela para obtener la protección de sus derechos, se produciría una mayor congestión judicial.

Efectivamente, al revisar la situación de las familias desplazadas por la violencia, se encontraron cumplidos cada uno de los factores determinados por la alta corporación, por lo que se impartieron las siguientes órdenes judiciales:

En el caso presente, la Sala dará dos tipos de órdenes. Unas órdenes de ejecución compleja, relacionadas con el Estado de cosas inconstitucionales y dirigidas a garantizar los derechos de toda la población desplazada, independientemente de que haya o no acudido a la acción de tutela para la protección de sus derechos. Tales órdenes tienen como finalidad que las entidades encargadas de atender a la población desplazada establezcan, en un plazo prudencial, y dentro de la órbita de sus competencias, los correctivos que sean necesarios para superar los problemas de insuficiencia de recursos destinados y de precariedad de la capacidad institucional para implementar la política estatal de atención a la población desplazada. Las órdenes de carácter simple que también se dictarán en este proceso están dirigidas a responder las peticiones concretas de los actores en la presente acción de tutela, y resultan compatibles con la línea jurisprudencial de la Corte Constitucional para la protección de los derechos de la población en situación de desplazamiento [...]

Dado que el Consejo Nacional de Atención Integral a la Población Desplazada es el órgano encargado de formular la política y de garantizar la asignación presupuestal para los programas de atención a la población desplazada, la Sala le comunicará del estado de cosas inconstitucional para que sea esta instancia la que determine la forma como pueda superarse la insuficiencia de recursos y las falencias en la capacidad institucional. El Consejo Nacional de Atención Integral a la Población Desplazada, en un plazo máximo de 6 meses, contados a partir de la comunicación de la presente sentencia, deberá concluir las acciones encaminadas a que todos los desplazados gocen efectivamente del mínimo de protección de sus derechos $[\ldots]$

Por la vía de la insuficiente apropiación presupuestal y de la omisión en la corrección de las principales falencias de la capacidad institucional, el avance progresivo en la satisfacción de los derechos de la población desplazada no sólo se ha retrasado, sino que se ha ido deteriorando con el paso del tiempo en algunos aspectos. Dicho retroceso es, prima facie, contrario al mandato constitucional de garantizar el goce efectivo de los derechos de todos los desplazados. Por eso, el primer deber de las autoridades competentes es evitar dicho retroceso práctico en los aspectos del nivel de protección de los derechos de todos los 
desplazados donde éste se ha presentado, así dicho retroceso sea resultado de la evolución del problema y de factores que escaparon a la voluntad de los funcionarios responsables.

No obstante, a la orden compleja emitida por la Corte Constitucional al Consejo Nacional de Atención Integral a la Población Desplazada, dicha corporación estableció una sala especial de seguimiento a la sentencia mencionada y a sus autos de cumplimiento, de tal modo, que en el Auto 314 de 2009 se ordenaron acciones concretas a las entidades del orden nacional, departamental y municipal, a fin de hacer efectiva la solución del problema de lo declarado inconstitucional, es decir, se determinó hacer seguimiento a la actividad administrativa de cada entidad territorial con relación a las ordenes emitidas.

En concordancia a tales acciones concretas y ordenadas con destino a los municipios, la Corte se pronunció diciendo:

Las entidades territoriales tendrán en cuenta un enfoque de derechos relacionados con cada uno de los componentes de la política pública de atención integral a población desplazada: ... política de vivienda, de tierras, y la estabilización socio-económica de las víctimas del desplazamiento forzado, de conformidad con la jurisprudencia de esta Corte. Así mismo, las autoridades administrativas de orden territorial tendrán en cuenta un enfoque diferencial, referido al logro del goce efectivo de los derechos de las mujeres, niños, indígenas, afrodescendientes y personas con discapacidad, de conformidad con los Autos 092 de 2008, 592 de 2008, 004 de 2009, 005 de 2009 y 006 de 2009.

Igualmente, la alta corporación vinculando a los municipios precisó:

Los gobiernos locales deberán rendir un informe a la Corte acerca del mandato contenido en el parágrafo $1^{\circ}$ del artículo $2^{\circ}$ de la Ley 1190 de 2008, que determina la obligación de los gobernadores y alcaldes municipales y distritales, de (i) la identificación y caracterización de la población en situación de desplazamiento ubicada en el departamento, el municipio y/o el distrito con indicación de los factores de riesgos que pudieran incrementarlo; (ii) información del nivel de atención actual a la población desplazada ya identificada, indicando el número de población atendida, la evolución del presupuesto asignado y ejecutado para la atención a la población desplazada, discriminando lo destinado según componentes y programas; (iii) la determinación de cuáles son las prioridades de atención y los recursos físicos, humanos, logísticos, económicos y técnicos con que cuenta cada entidad territorial para atender a la población desplazada; (iv) la identificación de los factores que han incluido en el compromiso presupuestal y administrativo efectivo de cada entidad territorial.

Lo anterior indica que no es la población afectada la que debe estar haciendo peticiones continuas ante las entidades públicas en procura de que se les restablezcan sus derechos, sino que son dichas entidades las que deben estar atentas a conocer las necesidades de la población discriminada y procurar el restablecimiento efectivo de 
sus derechos; queda entonces claro, que cualquier retraso o retroceso, es imputable a las autoridades públicas encargadas de dicha actividad y no la población afectada. En este aspecto, se debe aclarar que una vez las personerías notifican al municipio de la presentación de una queja por desplazamiento forzado, es deber del notificado iniciar el proceso administrativo de caracterización, con el objeto de vincular a dicho núcleo familiar en programas de vivienda, tierras o economía sostenible; es decir, la responsabilidad queda solo en cabeza de las autoridades públicas, y no en las familias victimizadas por dicho fenómeno ilegal.

De otra parte, la misma corporación en cumplimiento del Auto 314 de 2009, mediante el cual se ordenó la celebración de la sesión técnica de seguimiento a las órdenes impartidas en la Sentencia T-025 de 2004, y con fundamento en los informes que los gobiernos locales presentaron en dicha diligencia, emanó el Auto 383 de 2010, en el que reiteró la persistencia del estado de cosas inconstitucionales que soporta la población en situación de desplazamiento forzado, incluyéndose los derechos a vivienda digna, tierras y economía sostenible y en dicho pronunciamiento se refirió de manera concreta:

Un resumen de los informes presentados a la Corte con ocasión de las sesiones técnicas se encuentra en el Anexo I de este Auto. Dichos informes han servido de sustento para el análisis y adopción de decisiones previstas en este auto [...] Igualmente, ORDENAR a las autoridades de las entidades territoriales que requieran la ayuda del gobierno nacional en materia presupuestal, que antes del 30 de julio de 2011 realicen la respectiva solicitud debidamente sustentada. Si el gobierno no responde expresamente la solicitud antes del 30 de septiembre de 2011, se entenderá que el gobierno brindará el apoyo en los términos solicitados por la entidad territorial. Y a la inversa, si la entidad territorial no presenta la solicitud oportunamente, se presumirá que cuenta con el presupuesto necesario para atender debidamente a las víctimas del desplazamiento forzado en su territorio.

De igual manera, es relevante señalar cómo la Honorable Corporación, en dicho pronunciamiento, se refirió concretamente al departamento de Arauca en los siguientes términos:

Toda vez que algunas entidades territoriales a pesar de contar con recursos para la atención a la población desplazada, y enfrentar una situación humanitaria crítica en materia de desplazamiento forzado interno, de manera palmaria e injustificada dejan de cumplir con sus responsabilidades con la población desplazada, por ejemplo, mediante una asignación presupuestal desproporcionadamente inferior a la magnitud del problema y la capacidad financiera de la entidad, a fin de que sean otras entidades territoriales las que asuman dicha carga, la Corte ordenará al Departamento Nacional de Planeación, elaborar e implementar una fórmula que tenga en cuenta los factores antes mencionados y otros que considere relevantes, con arreglo a la cual se individualicen dichas entidades renuentes en situación crítica, y conjuntamente 
con el Ministerio del Interior y de Justicia y el Ministerio de Hacienda y Crédito Público, diseñen y adopten medidas específicas para superar esta desproporción inconstitucional y mejorar el compromiso territorial en la superación del estado de cosas inconstitucional. Con el fin de probar la efectividad de la fórmula adoptada, se sugiere hacer un pilotaje en los departamentos del Huila y del Arauca, dado el nivel de compromiso mostrado por estas entidades y la gravedad de la situación humanitaria enfrentada (subrayado fuera de texto).

De manera concreta, se puede afirmar que las acciones administrativas mínimas y obligatorias determinadas por la Corte Constitucional en cabeza de los municipios, y que a la fecha deben estar ejecutadas a fin de hacer efectivo los derechos de las familias afectadas por el desplazamiento forzado y residenciadas en la jurisdicción de Saravena, Arauca son: i) Caracterización de la totalidad de la población desplazada por la violencia que reside en esta jurisdicción; ii) Identificación de cuáles son las familias que solicitan vivienda digna, tierras o economía sostenible; iii) Proyectos ejecutados o en ejecución que vincule a todas las familias o personas que reclaman estos derechos o al menos uno de ellos; y iv) Haber solicitado la ayuda del Gobierno nacional en materia presupuestal debidamente sustentada, antes del 30 de julio de 2011.

Por lo anterior, es que se hace interesante conocer el estado actual en que se encuentra la población desplazada por la violencia y asentada en el municipio de Saravena, Arauca, pues existiendo parámetros establecidos por la Honorable Corte Constitucional, es posible conocer si los hechos que generan el estado de cosas inconstitucional se mantienen en similares condiciones, se han superado o en el peor de los casos son más gravosos.

\section{REALIDAD DEL DESPLAZAMIENTO EN EL MUNICIPIO DE SARAVENA, ARAUCA}

\section{Ubicación del municipio y descripción de su zona urbana y rural}

El municipio de Saravena está situado en la Orinoquia colombiana, noroccidente del departamento de Arauca. Sus coordenadas geográficas son: Latitud norte entre 6 grados 46' y 7 grados 00 ' y en la Longitud este entre 71 grados 41 ' y 72 grados 06 '. La extensión del municipio es de 658,7 kilómetros cuadrados, equivalente al $2.79 \%$ del departamento de Arauca ${ }^{1}$.

1 El territorio municipal está conformado por el espacio geográfico comprendido dentro de los límites establecidos por el polígono trazado por los puntos 903719,125-1267163,63 en la confluencia del río Bojabá con el río Arauca, por este sigue hacia el oriente hasta el punto 931998,909-1269985, rumbo sur hasta el 934518-1251973, luego hacia el suroccidente hasta 924640-1244978 sigue hacia el punto $900206,438-1239996,88$, de allí hasta $887110,187-1237884,25$ y de allí hacia el norte hasta el punto de inicio (fuente página web Planeación Nacional) 


\section{Zona Rural}

Sector rural dividido en once distritos, conformados por 78 veredas y 2500 predios rurales. Así mismo, allí se localizan el sector indígena con seis comunidades y la inspección de policía de Puerto Nariño.

Figura 1. División Política. Municipio de Saravena

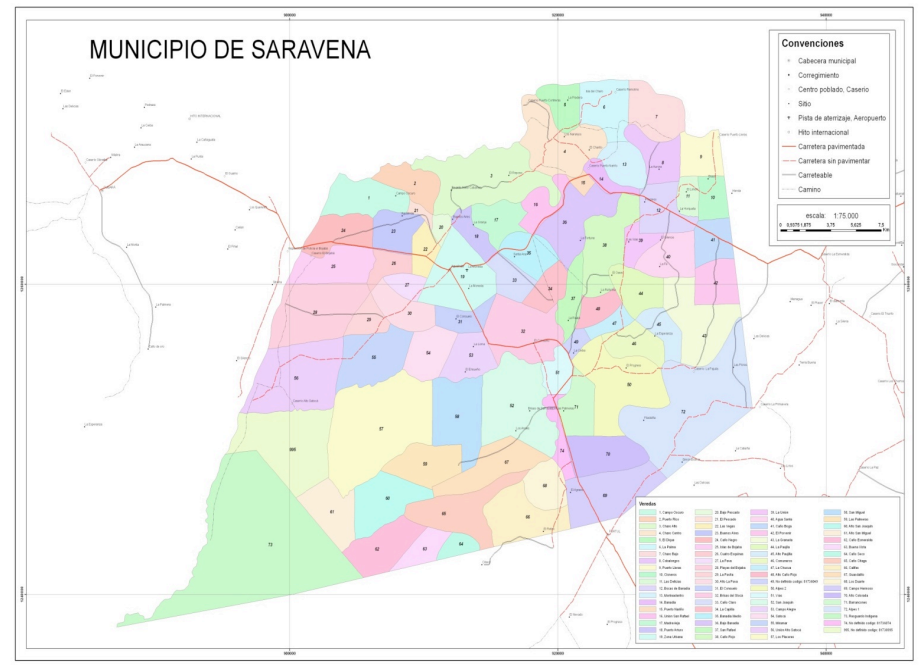

Fuente: Alcaldía de Saravena.

La organización administrativa del área rural se presenta dividida en Distritos ${ }^{2} \mathrm{y}$ estos en veredas.

2 Distrito 1: Campo Oscuro, Caño Negro, El Pescado, Buenos Aires, Cuatro Esquinas, Las Vegas, Bajo Pescado, La Pava. Distrito 2: Puerto Rico, Charo Alto, Charo Centro, Charo Centro 2, El Dique, La Palma, Charo Bajo, Charo Bajo 2, Monteadentro. Distrito 3: Cobalongos, Puerto Lleras, Las Delicias, Cisneros, Bocas de Banadia, La Unión, Banadia. Distrito 4: Agua Santa, Caño Boga, El Porvenir, La Granada. Distrito 5: San Rafael, Caño Rojo, Alto Caño Rojo, La Pajuila, La Chucua, La Capilla, Comuneros y Alto la Pajuila. Distrito 6: Puerto Arturo, Madrevieja 1, Madrevieja 2, Unión San Rafael, Puerto Nariño, Bajo Banadia, Caño Claro, Banadia Medio, Bello Horizonte, La Unión Inspección Puerto Nariño. Distrito 7: El Consuelo, Brisas del Satocá, Campo Alegre, Satocá, Miramar, Unión Alto Satocá, Los Placeres, Alto San Miguel. Distrito 8: Islas del Bojabá, Playas del Bojabá, La Pavita, Alto la Pava. Distrito 9: Alto San Joaquín, Los Andes, Las Palmeras, Guasdualito, San Joaquín Bajo, San Miguel Dos. Distrito 10: Caño Esmeralda, Buena Vista, Caño Seco, Alto Citacá, Calafitas, Los Duartes. Distrito 11: Vías, Barrancones, Alpes I, Alpes II, Alto La Colorada, Campo Hermoso. Comunidad Indígena: Calafitas I, Calafitas II, Playas del Bojabá, Valles del Sol. Sin embargo, aunque esta propuesta comunitaria de organización no está reglamentada por el Concejo Municipal, funcionalmente es aceptada por los distintos actores de la localidad. 


\section{Zona Urbana}

En la realización de foros participativos por sectores se definió organizar administrativamente el municipio en sector urbano, dividido en cuatro comunas, conformadas por 34 barrios normales, 4 barrios subnormales y 6225 predios urbanos.

\section{Población del municipio: población según estadísticas del DANE}

El desarrollo urbano de Saravena se explica por su condición de epicentro de la colonización del Sarare. La población de Saravena, según el DANE, es de 43732 habitantes, de los cuales 29320 están en el área urbana y 14412 en el área rural.

Tabla 1. Población según datos del SISBEN a 31 de diciembre de 2010

\begin{tabular}{|l|l|}
\hline Población sisbenizada & 56246 \\
\hline Población urbana & 40220 \\
\hline Población rural y centros poblados & 16029 \\
\hline Población femenina & 27848 \\
\hline Población masculino & 28398 \\
\hline Población indígena & 920 \\
\hline Población afrodescendiente & 1150 \\
\hline
\end{tabular}

Fuente: SISBEN, 2011.

Tabla 2. Población sisbenizada y discriminada por edades a 31 de diciembre de 2010

\begin{tabular}{|c|c|}
\hline Edad & No. de personas \\
\hline 0 a 7 años & 8184 \\
\hline 8 a 18 años & 12412 \\
\hline 19 a 25 años & 7813 \\
\hline 26 a 65 años & 23404 \\
\hline 66 años en adelante & 4433 \\
\hline Total & $\mathbf{5 6 2 4 6}$ \\
\hline
\end{tabular}

Fuente: SISBEN 2011. 
Tabla 3. Necesidades Básicas Insatisfechas - NBI, por total, cabecera y resto, según municipio y nacional a julio 30 de 2010

\begin{tabular}{|c|c|c|c|c|c|c|c|c|c|}
\hline \multirow{2}{*}{$\begin{array}{c}\text { Código } \\
\text { Dpto. }\end{array}$} & \multirow{2}{*}{$\begin{array}{c}\text { Nombre } \\
\text { Dpto. }\end{array}$} & \multirow{2}{*}{$\begin{array}{c}\text { Código } \\
\text { Municipio }\end{array}$} & \multirow{2}{*}{$\begin{array}{c}\text { Nombre } \\
\text { Municipio }\end{array}$} & & & \multicolumn{6}{|c|}{ Personas en NBI } \\
\cline { 5 - 10 } & & & $\begin{array}{c}\text { Cabecera } \\
(\%)\end{array}$ & cve (\%) & $\begin{array}{c}\text { Prop } \\
(\%)\end{array}$ & $\begin{array}{c}\text { cve } \\
(\%)\end{array}$ & $\begin{array}{c}\text { Prop } \\
(\%)\end{array}$ & $\begin{array}{c}\text { cve } \\
(\%)\end{array}$ \\
\hline 81 & Arauca & 736 & Saravena & 28,33 & 9,38 & 59,22 & 1,63 & 34,15 & 6,34 \\
\hline
\end{tabular}

Fuente: Resultados Censo General, 2005. DANE. 2011.

\section{Dinámica del desplazamiento en Saravena}

El municipio de Saravena está ubicado estratégicamente por su zona de influencia en el piedemonte araucano, sector fronterizo con la República Bolivariana de Venezuela, corredor vial obligatorio con los departamentos de Boyacá, Norte de Santander, Santander y el Nororiente colombiano, esta situación se ha convertido desde hace cincuenta años en el corredor estratégico de los grupos armados al margen de la ley, el narcotráfico y la delincuencia común que ha fortalecido su actuar por la geografía y la obligatoriedad del tránsito por estos sectores. Otro de los factores que genera la presencia de los Actores Armados Ilegales AAI es la economía informal y el contrabando, lo mismo que la presencia de Ecopetrol y las contratistas, la extorsión a los ganaderos, grandes y pequeños comerciantes, el secuestro y otras situaciones que hacen de esta zona estratégica para la presencia de estos grupos.

Históricamente ha sido uno de las zonas del país con una situación crítica de conflicto armado que ha agudizado la problemática de miles de saraveños que desde el campo y la ciudad ven disminuidas sus posibilidades del goce de una mejor calidad, disfrute y mejoramiento de las condiciones de vida.

En buena medida, las estrategias de guerra que utilizan los grupos ilegales están plenamente relacionadas con el debilitamiento de la base social, implicando dentro de sus acciones a grupos campesinos, líderes sociales, ciudadanía en general, entre otros. La situación de polarización y lucha de intereses de los actores al margen de la ley ha generado tanto en el ámbito regional como local desplazamientos forzados, guerra sicológica, homicidios selectivos en gran cantidad, y múltiples amenazas e intimidaciones a líderes de las organizaciones sociales, no solo a nivel del municipio sino de toda la zona en el departamento de Arauca. Muchas de estas expresiones de violencia también pueden estar ligadas al fenómeno del narcotráfico, actividad que desarrollan para el sostenimiento de su economía militar.

Otra de las causas en menor proporción son las determinadas por las fuerzas del Estado, que al acampar dentro de propiedades de campesinos comunes y corrientes, escuelas, y otras zonas especiales, ponen en riesgo permanente a la comunidad por la polarización de la guerra, y lastimosamente algunos miembros de la fuerza pública utilizan el terrorismo psicológico en contra de esta población generando también los desplazamientos forzados. 
Expulsor

Tabla 4. El nivel de expulsión de personas

\begin{tabular}{|c|c|c|c|c|c|c|c|c|c|c|c|c|c|c|c|c|}
\hline \multicolumn{10}{|c|}{ Año salida } \\
\hline ND & $\mathbf{1 9 9 7}$ & $\mathbf{1 9 9 8}$ & $\mathbf{1 9 9 9}$ & $\mathbf{2 0 0 0}$ & $\mathbf{2 0 0 1}$ & $\mathbf{2 0 0 2}$ & $\mathbf{2 0 0 3}$ & $\mathbf{2 0 0 4}$ & $\mathbf{2 0 0 5}$ & $\mathbf{2 0 0 6}$ & $\mathbf{2 0 0 7}$ & $\mathbf{2 0 0 8}$ & $\mathbf{2 0 0 9}$ & $\mathbf{2 0 1 0}$ & $\mathbf{2 0 1 1}$ & $\begin{array}{c}\text { Total } \\
\text { general }\end{array}$ \\
\hline 95 & 201 & 51 & 66 & 219 & 317 & 513 & 639 & 743 & 575 & 1.010 & 1449 & 1337 & 836 & 512 & 90 & 8653 \\
\hline
\end{tabular}

Fuente: Acción Social, mayo 31 de 2011.

Tabla 5. Expulsión de hogares

\begin{tabular}{|c|c|c|c|c|c|c|c|c|c|c|c|c|c|c|c|c|}
\hline $\mathbf{1 0}$ & Año salida \\
\hline 32 & $\mathbf{1 9 9 7}$ & $\mathbf{1 9 9 8}$ & $\mathbf{1 9 9 9}$ & $\mathbf{2 0 0 0}$ & $\mathbf{2 0 0 1}$ & $\mathbf{2 0 0 2}$ & $\mathbf{2 0 0 3}$ & $\mathbf{2 0 0 4}$ & $\mathbf{2 0 0 5}$ & $\mathbf{2 0 0 6}$ & $\mathbf{2 0 0 7}$ & $\mathbf{2 0 0 8}$ & $\mathbf{2 0 0 9}$ & $\mathbf{2 0 1 0}$ & $\mathbf{2 0 1 1}$ & $\begin{array}{c}\text { Total } \\
\text { general }\end{array}$ \\
\hline
\end{tabular}

Fuente: Acción Social, mayo 31 de 2011.

\section{Recepción}

Tabla 6. Registro de población en situación de desplazada a 31 de mayo de 2011

\begin{tabular}{|c|c|c|c|c|c|c|c|c|c|c|c|c|c|c|c|c|c|c|}
\hline \multirow{2}{*}{$\begin{array}{c}\text { Dpto. } \\
\text { receptor }\end{array}$} & $\begin{array}{c}\text { Municipio } \\
\text { receptor }\end{array}$ & ND & $\mathbf{1 9 9 7}$ & $\mathbf{1 9 9 8}$ & $\mathbf{1 9 9 9}$ & $\mathbf{2 0 0 0}$ & $\mathbf{2 0 0 1}$ & $\mathbf{2 0 0 2}$ & $\mathbf{2 0 0 3}$ & $\mathbf{2 0 0 4}$ & $\mathbf{2 0 0 5}$ & $\mathbf{2 0 0 6}$ & $\mathbf{2 0 0 7}$ & $\mathbf{2 0 0 8}$ & $\mathbf{2 0 0 9}$ & $\mathbf{2 0 1 0}$ & $\mathbf{2 0 1 1}$ & $\begin{array}{c}\text { Total } \\
\text { gral }\end{array}$ \\
\hline Arauca & Saravena & & 19 & 9 & 8 & 16 & 31 & 29 & 442 & 631 & 338 & 1599 & 1.679 & 2611 & 606 & 378 & 42 & 8438 \\
\hline
\end{tabular}

Fuente: Acción Social, 2011.

Tabla 7. Registro de familias en situación de desplazamiento a 31 de mayo de 2011

\begin{tabular}{|c|c|c|c|c|c|c|c|c|c|c|c|c|c|c|c|c|c|c|}
\hline \multirow{2}{*}{$\begin{array}{c}\text { Dpto. } \\
\text { receptor }\end{array}$} & $\begin{array}{c}\text { Municipio } \\
\text { receptor }\end{array}$ & ND & $\mathbf{1 9 9 7}$ & $\mathbf{1 9 9 8}$ & $\mathbf{1 9 9 9}$ & $\mathbf{2 0 0 0}$ & $\mathbf{2 0 0 1}$ & $\mathbf{2 0 0 2}$ & $\mathbf{2 0 0 3}$ & $\mathbf{2 0 0 4}$ & $\mathbf{2 0 0 5}$ & $\mathbf{2 0 0 6}$ & $\mathbf{2 0 0 7}$ & $\mathbf{2 0 0 8}$ & $\mathbf{2 0 0 9}$ & $\mathbf{2 0 1 0}$ & $\mathbf{2 0 1 1}$ & $\begin{array}{c}\text { Total } \\
\text { general }\end{array}$ \\
\hline Arauca & Saravena & & 5 & 2 & 2 & 4 & 7 & 6 & 106 & 114 & 77 & 346 & 388 & 649 & 163 & 111 & 9 & 1989 \\
\hline
\end{tabular}

Fuente: Acción Social, 2011. 
Tabla 8. Valoración mapa de riesgo zona rural Saravena

\begin{tabular}{|c|c|c|c|c|c|c|c|c|c|c|c|}
\hline $\begin{array}{c}\text { Alto } \\
\text { Riesgo }\end{array}$ & $\begin{array}{c}\text { Campo } \\
\text { Oscuro }\end{array}$ & $\begin{array}{c}\text { Caño } \\
\text { Negro }\end{array}$ & $\begin{array}{c}\text { EI } \\
\text { Pescado }\end{array}$ & $\begin{array}{c}\text { Puerto } \\
\text { Rico }\end{array}$ & $\begin{array}{c}\text { Charo } \\
\text { Alto }\end{array}$ & $\begin{array}{c}\text { Charo } \\
\text { Centro }\end{array}$ & $\begin{array}{c}\text { Charo } \\
\text { Centro 2 }\end{array}$ & $\begin{array}{c}\text { El } \\
\text { Dique }\end{array}$ & $\begin{array}{c}\text { La } \\
\text { Palma }\end{array}$ & $\begin{array}{c}\text { Puerto } \\
\text { Lleras }\end{array}$ & $\begin{array}{c}\text { Inspección } \\
\text { Puerto Nariño }\end{array}$ \\
\hline & 38 & 37 & 37 & 34 & 35 & 35 & 34 & 34 & 34 & 39 & 35 \\
\hline
\end{tabular}

Fuente: Defensoría Delegada para la Evaluación del Riesgo 2011.

La situación de conflicto armado en el departamento de Arauca entre los actores de la guerra ha condenado al desplazamiento forzado a cerca 60000 personas de diferentes edades, no solamente de otros municipios del departamento sino además de población desplazada de otros sitios del país. El desplazamiento implica una crisis personal y familiar que conduce al deterioro acelerado de las condiciones materiales de vida. La consecuencia inmediata es la insatisfacción de necesidades básicas de la población asociada con frecuencia a la falta de garantías para la protección a la vida y la integridad física. Como es bien sabido la presencia de los grupos armados ilegales en el departamento de Arauca es de amplia cobertura y, por ello, Saravena no es la excepción, según lo reporta el Informe de Riesgo del Sistema de Alertas Tempranas (SAT) de la Defensoría del Pueblo, dicha presencia se hace más fuerte en algunas zonas como lo son los centros poblados de Puerto Contreras y Puerto Lleras, además de las veredas limítrofes entre los municipios de Saravena, Tame y Arauquita. La situación social del departamento también ha generado una serie de desplazamientos a nivel interno del casco urbano del municipio, esta modalidad es más baja, sin embargo, se presenta.

\section{Caracterización de familias desplazadas residentes en el municipio de Saravena}

Para lograr el objetivo propuesto, desde el diseño metodológico se caracterizó la población mencionada, actividad que se realizó a partir del modelo de ficha entrevista- diligencia, sujeta al art. 15 de Decreto 1569 de 2000 -Ministerio del Interior y de Justicia, Principio de confidencialidad-, por lo que en procura de conocer la mayor información con relación a esta población y hacer más precisa la investigación, referente a los derechos a vivienda digna, tierras y economía sostenible, se convocó mediante la emisora local "FM Sarare Stereo" con sede en Saravena, Arauca y amplia sintonía, a todas las familias residenciadas en el municipio, dicha convocatoria duró vigente por espacio de treinta días hábiles, y se obtuvo una muestra de 943 personas que dijeron representar igual número de núcleos familiares, con el siguiente resultado: 
Figura 2. Grupos etarios

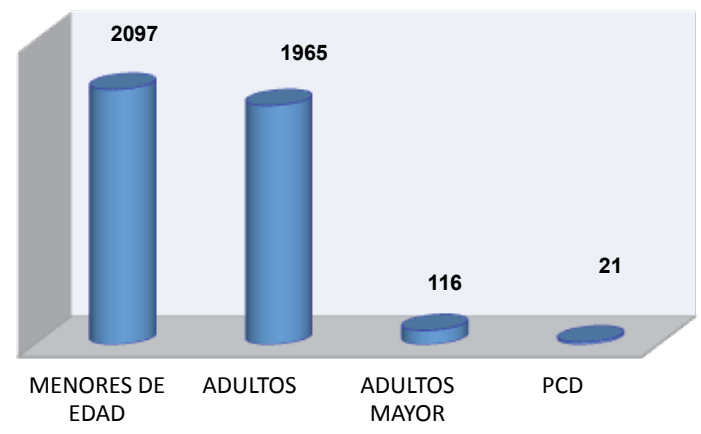

Fuente: elaboración propia.

Con el objeto de conocer la existencia de personas con especial protección por la Constitución Política se analizó la muestra en forma etérea, arrojando un resultado de 2097 personas menores de edad, 116 adultos mayores y 21 con discapacidad física, es decir, un total de 2234 personas con protección especial por la C.N. y 1965 personas adultas, para un total de 4199 personas en estado de desplazamiento forzado.

Figura 3. Ubicación unidades de vivienda de los núcleos familiares

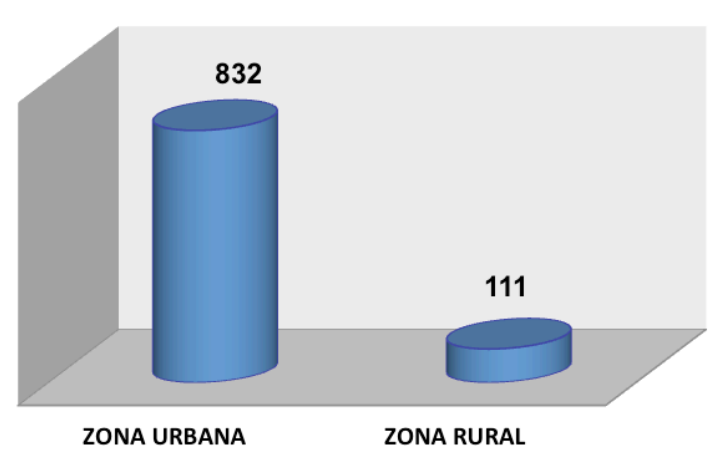

Fuente: elaboración propia.

Con el fin de conocer el asentamiento de las familias, y poder discriminar si prefieren establecer su forma de vida en la zona urbana o rural, se clasificó la información, determinando que de los 943 núcleos familiares, 832 núcleos se encuentran en la zona urbana y 111 en la zona rural del municipio de Saravena, Arauca. 
Figura 4. Restablecimiento del derecho a tener una vivienda digna

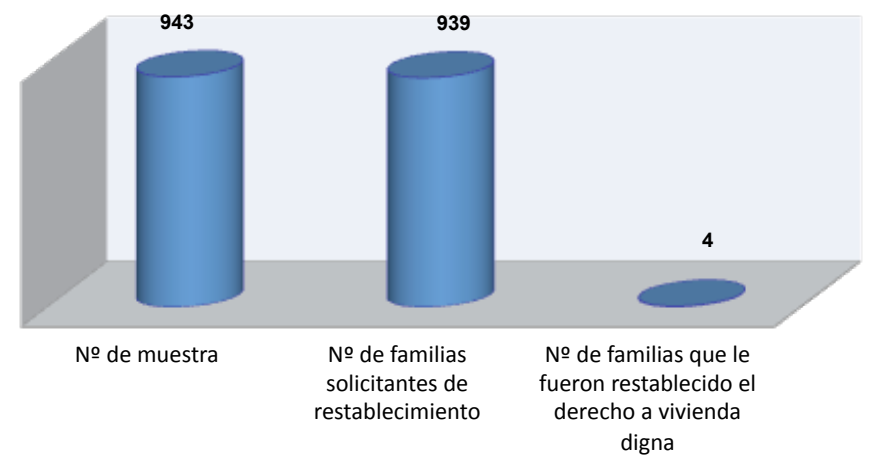

Fuente: elaboración propia.

En cuanto al restablecimiento del derecho a vivienda digna, de las 943 muestras, un número de 939 solicitan restablecimiento del derecho, mientras que 4 núcleos manifestaron haber recibido subsidio para compra de vivienda después de su desplazamiento forzado. Con referencia a este derecho, hay 939 núcleos familiares a los que no se ha restablecido la condición inconstitucional.

Figura 5. Entidad que restableció el derecho a vivienda digna
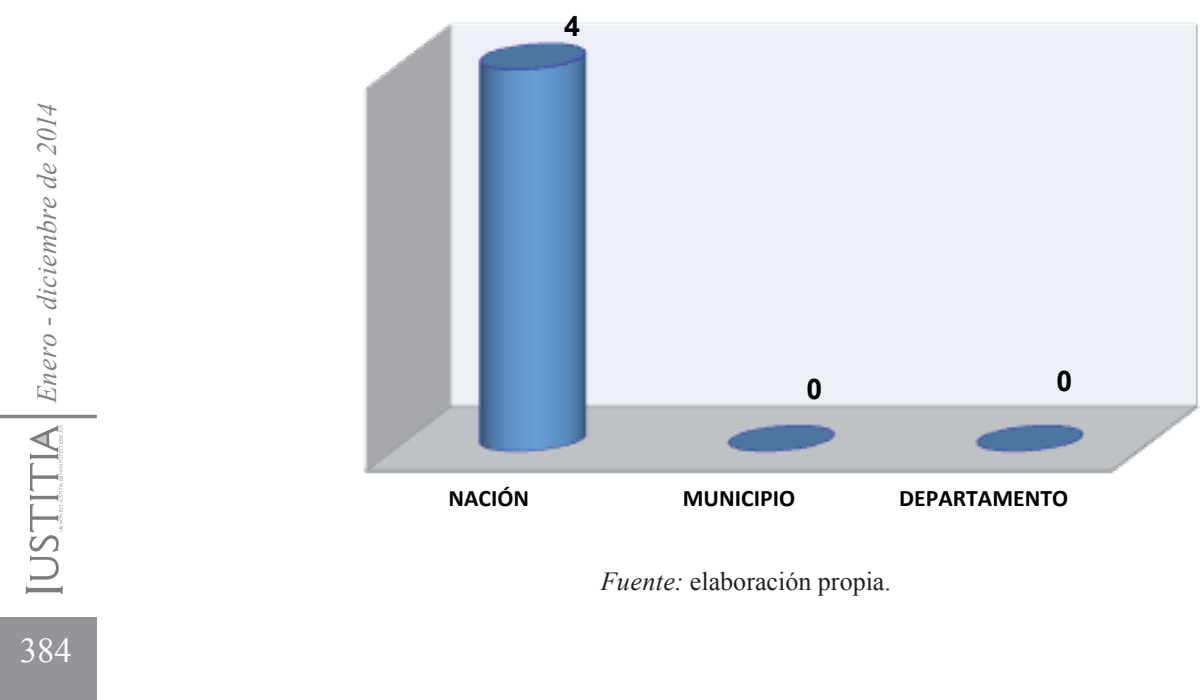

Fuente: elaboración propia. 
De las entrevistas, se verificó que la entidad, en cuatro casos concretos, respondió a las necesidades de las familias en materia de vivienda digna, se pudo verificar que fue la Nación la encargada de tales diligencias.

Figura 6. Restablecimiento del derecho de tierras o reubicación

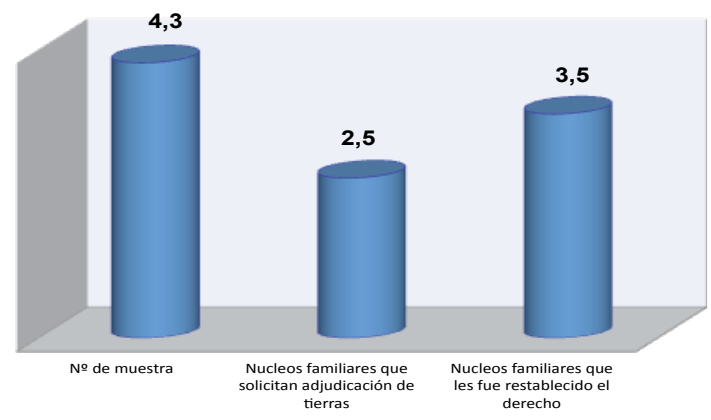

Fuente: elaboración propia.

Analizada la información generada en la caracterización, se verificó que de las 943 muestras, un número de 700 familias solicitan restablecimiento del derecho a tierras, mientras que solo un 1 un núcleo manifestó haber recibido subsidio para compra de tierras después de su desplazamiento forzado. Esta información permite afirmar que actualmente existe un gran número de núcleos familiares bajo un estado de cosas inconstitucional; no obstante, esta situación se determinará de fondo al momento de conocer la actividad administrativa por la entidad territorial, la cual debe consistir en proyectos ejecutados o en proceso, en procura de dar solución a la problemática, y que indicará si hay retraso o inclusive retroceso en la atención integral a la problemática señalada.

Figura 7. Entidad que restableció el derecho a tierras

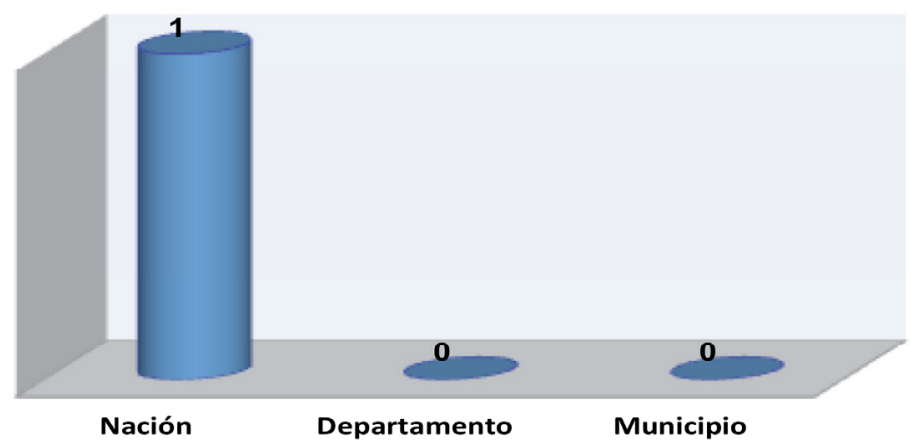

Fuente: elaboración propia. 
La información recolectada demuestra que la respuesta a la necesidad del único núcleo familiar que se le restableció el derecho a tierras fue igualmente actividad de la Nación. Sobre el particular es obligatorio precisar que lo que interesa para la Corte Constitucional no es quién en últimas consolida el restablecimiento del derecho, sino la gestión o intervención real, oportuna y eficaz del municipio en favor de las víctimas del estado de cosas inconstitucional.

Figura 8. Restablecimiento del derecho a tener una economía sostenible

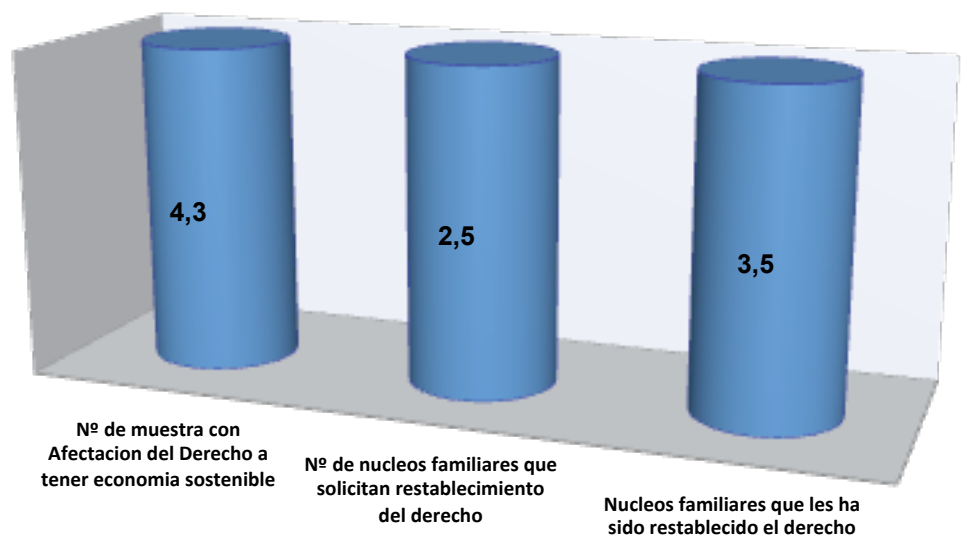

Fuente: elaboración propia.

Con relación al derecho a tener una economía sostenible, al observar los resultados expuestos en la gráfica, se encuentra un resultado similar a los anteriores, pues de las 943 muestras, un número de 888 solicitan restablecimiento del derecho a una economía sostenible, mientras que solo 14 núcleos manifestaron haber recibido subsidio para restablecimiento del derecho. Al observar el resultado, de manera llana o elemental, se concluye que solo a una mínima cantidad de núcleos familiares, es decir, 14 frente a 888 que solicitan el derecho a economía sostenible, se les ha dado respuesta efectiva a su necesidad, razón que avizora potencialmente el mantenimiento del estado de cosas inconstitucionales en esta materia y con relación a la población asentada en Saravena, Arauca. 
Figura 9. Entidad que restableció el derecho a tener una economía sostenible

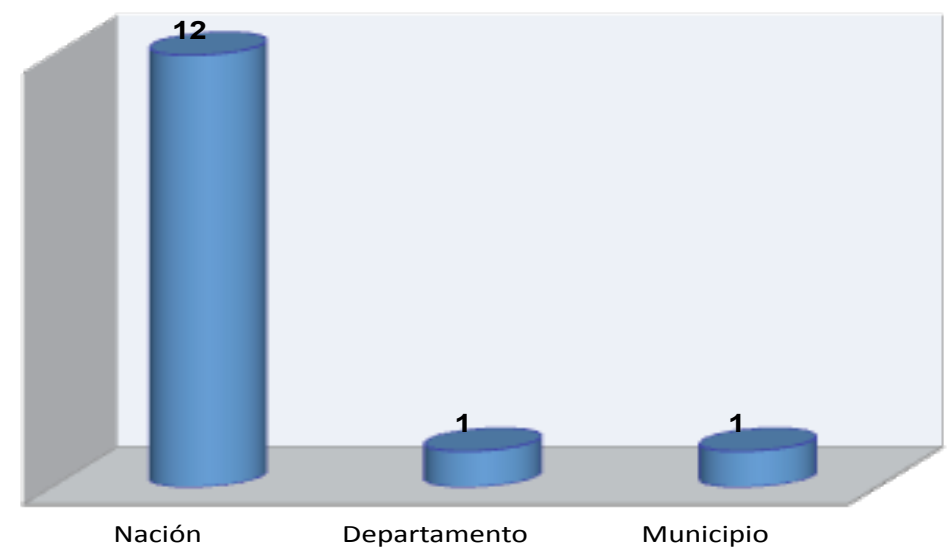

Fuente: elaboración propia.

Como se pudo observar, la anterior información, la cual tiene como fuente de manera directa la población afectada, permitió de modo inequívoco conocer la población existente bajo enfoque diferencial, sus necesidades en materia de vivienda, tierras y economía sostenible, y la respuesta institucional del Gobierno nacional, departamental y municipal.

\section{Gestión administrativa del municipio de Saravena frente a los derechos de los desplazados}

Para verificar el cumplimiento o no de dichas obligaciones se realizó visita a la Oficina de Planeación del Municipio, por parte de la cual se informó, que hasta la fecha la actividad en procura de restablecer los derechos ya mencionados a la población en situación de desplazamiento forzado por la violencia dentro del marco del conflicto interno armado y residenciada en esta jurisdicción municipal, fueron las siguientes:

1. A la fecha en el municipio no se ha hecho efectivo el restablecimiento del derecho a vivienda digna a ninguna familia, que solo existe un proyecto en ejecución encaminado a dar solución a un número de ciento cincuenta núcleos, proyecto que cuenta con la intervención del Banco Agrario, el departamento de Arauca y el municipio de Saravena. 
2. Con relación a los derechos a tierras y economía sostenible, el funcionario argumentó que el municipio no ha hecho efectivo el restablecimiento de dichos derechos a estas familias; tampoco se conoce la existencia de proyectos o programas al respecto, o gestiones formales que tiendan a provocar la concurrencia o subsidiariedad de entidades departamentales o del orden Nacional en procura de dar solución al problema mencionado.

De otra parte, en materia del Plan Integral Único para la atención a población en situación de desplazamiento forzado-PIU- se afirma por parte de la asesoría municipal, que el ente territorial actualmente no cuenta con un sistema de caracterización de dichas familias, excusando al municipio con el argumento de enfrentar limitaciones del orden fiscal. De igual manera, debido que no se tiene una caracterización propia, el municipio no tiene información precisa, de cuáles y cuántos son los núcleos familiares que solicitan restablecimiento del derecho a vivienda digna, tierras y economía sostenible. También señaló que con motivo de la orden impartida por la Honorable Corte Constitucional mediante el Auto de Seguimiento 383 de 2010, el día 28 de julio de 2011, -dos días antes del vencimiento del tiempo perentorio- y aprovechando la información recogida en esta investigación, la cual se ha hecho de público conocimiento, el municipio de Saravena radicó ante Planeación Nacional y el Ministerio del Interior y de Justicia, la ficha presupuestal, mediante la cual solicitan el apoyo presupuestal de la Nación, con destino a restablecer el derecho de vivienda digna a un número de novecientas familias; igualmente, se solicitó apoyo presupuestal con el objeto de restablecer los derechos a economía sostenible de quinientos ochenta núcleos familiares. Con relación al derecho de tierras, expresó que no se pidió apoyo presupuestal, por cuanto está planteado que dicho problema será resuelto por el departamento de Arauca en su jurisdicción, incluyendo naturalmente al municipio de Saravena.

Igualmente, se manifiesta que debido a la no existencia de caracterización de la población en situación de desplazamiento forzado y residenciada en esta jurisdicción, no es posible ofrecer una atención concreta y eficiente a cada núcleo familiar, pues de existir dicha caracterización, permitiría a las diferentes autoridades públicas, tener un diagnóstico real del asunto, por ejemplo, conocer cuáles y cuántas son las familias que reclaman restablecimiento de un determinado derecho; igualmente, la caracterización permitiría un cálculo real con relación a los valores que en materia presupuestal el municipio debe requerir de la Nación a fin de restablecer los derechos a todas las familias, y no a un número aproximado; y algo aún más relevante, permitirá realizar el trabajo institucional bajo la aplicación de un enfoque diferencial con relación a las personas de especial protección, tal como lo ha ordenado la Honorable Corporación. 


\section{CONCLUSIÓN}

Antes de concretar el objetivo general es preciso decir que la falta de caracterización de las familias en situación de desplazamiento forzado no solo ha generado un retardo, sino que es causa de retroceso en el restablecimiento de los derechos vulnerados a la población mencionada, pues la no sustentación correcta de las ayudas presupuestales solicitadas ante la Nación, potencialmente pueden redundar en la negación de dichos recursos hasta tanto no se realice la caracterización precisa de dichos núcleos familiares. Igualmente, se puede verificar que la inactividad administrativa del municipio hace cada vez más gravosa la situación de las personas afectadas, especialmente de quienes están enmarcadas como sujetos de especial protección constitucional, como son los menores, los de tercera de edad y personas en condición de discapacidad física o mental; y que en este caso concreto se tiene el $53.2 \%$, de sujetos bajo estas características que son la mayoría de los integrantes de dichos núcleos familiares.

Visto lo anterior, se concluye que actualmente la Nación, el departamento y el municipio no han cumplido las ordenes emitidas por la Honorable Corte Constitucional, razón que permite afirmar sin temor a equivocaciones, que los hechos generadores del estado de cosas inconstitucional que afectan gravemente la población víctima del desplazamiento forzado por la violencia dentro del marco del conflicto interno armado, al menos en el municipio de Saravena, Arauca, se mantiene en las mismas condiciones, de manera que estos núcleos familiares siguen viendo vulnerados sus derechos fundamentales a vivienda digna, tierras y economía sostenible.

De otra parte, el resultado de esta investigación demuestra claramente el desacato que los administradores de turno, del mismo orden nacional, departamental y local, con relación al municipio de Saravena Arauca han dado a las órdenes de la Honorable Corporación, y pareciera, que dichos pronunciamientos se han hecho una parte más del discurso institucional que trata la materia, sin que exista determinación de responsabilidad disciplinaria, fiscal o penal con relación a los comprometidos en tales omisiones; y no solo en este municipio, sino que valdría la pena investigarlo a lo largo y ancho del país, en municipios de similar categoría administrativa (sexta categoría), pues de ser generalizado el fenómeno, estaríamos frente a una pérdida relevante de autoridad por parte de la Corte Constitucional, o frente a fallos inocuos que por déficit fiscal en los gobiernos locales se hace imposible su cumplimiento. 


\section{REFERENCIAS}

Corte Constitucional. Sentencia T-025 de 2004, M. P. Manuel José Cepeda Espinosa, 22 de enero de 2004. Bogotá, D. C.

Corte Constitucional. Auto 314 de 2009, M. P. Luis Ernesto Vargas Silva, 29 de octubre de 2009.

Corte Constitucional. Auto 0383 de 2010, M. P. Luis Ernesto Vargas Silva, 10 de diciembre de 2010.

Departamento de Planeación Nacional. https://www.dnp.gov.co/Paginas/inicio.aspx

Documento PIU Municipio de Saravena. 